\title{
ARTIGO
}

do1 https://doi.org/10.22481/praxisedu.v16i41.6466

\section{POLÍTICAS EDUCACIONAIS DE ENSINO MÉDIO: UM OLHAR SOBRE A AÇÃO DO ESTADO PARAENSE DE 2007 A 2013}

\author{
HIGH SCHOOL EDUCATIONAL POLICIES: A LOOK AT THE ACTION OF THE \\ STATE OF Pará FROM 2007 TO 2013
}

\author{
POLÍTICAS EDUCATIVAS DE LA ESCUELA SECUNDARIA: UNA MIRADA A LA \\ ACCIÓN DEL ESTADO DE PARÁ DE 2007 A 2013
}

\author{
Afonso Welliton de Sousa Nascimento \\ Universidade Federal do Pará - Brasil \\ Yvens Ely Martins Cordeiro \\ Universidade Federal do Pará - Brasil \\ Francinei Bentes Tavares \\ Universidade Federal do Pará - Brasil \\ José Ribamar Furtado de Souza \\ Universidade Federal do Pará - Brasil
}

\begin{abstract}
Resumo: Este artigo faz uma interpretação da política educacional do Ensino Médio desenvolvido pelo Estado Paraense. Busca compreender como as políticas educacionais globais de cunho nacional, se incorporam às injunções locais e, ao mesmo tempo, como a partir de então, elas se constituíram em políticas locais e desenvolvidas com todo aparato do Estado, como elaborador, executor das políticas do Ensino Médio, envolvido com as dinâmicas, políticas e sociais locais que abrangem a realidade educacional. Estabelece-se assim a conexão sobre o sentido de classe assumido pelo Estado capitalista na evolução política nacional, em que a forma conservadora de desenvolvimento da economia desde a colonização incorporando na burocracia governamental os estamentos de classe próprio do período colonizador e, do sentido patrimonialista oligárquicos do desenvolvimento na república, constitui esse significado fisiológico presente na forma de organização e de gestão dos recursos públicos disponíveis na modernidade burguesa brasileira.
\end{abstract}

Palavras chave: Políticas educacionais; Ensino médio; Estado do Pará.

Abstract: This article makes an interpretation of the high school educational policy developed by the State of Pará. It seeks to understand how global educational policies of national nature are incorporated into local injunctions and, at the same time, as from then on, they were constituted in local policies and 
developed with all the apparatus of the State, as a developer, executor of Education policies Medium, involved with local dynamics, politics and social that encompass the educational reality. Thus, the connection about the sense of class assumed by the capitalist state in the national political evolution is established, in which the conservative form of development of the economy since colonization incorporating into the government bureaucracy the class estates proper of the colonizing period and, of the oligarchic patrimonial sense of development in the republic, this physiological meaning is present in the form of organization and management of public resources available in Brazilian bourgeois modernity.

Keywords: Educational policies; High school; State of Pará.

Resumen: Este artículo hace una interpretación de la política educativa de la escuela secundaria desarrollada por el Estado de Pará. Busca comprender cómo las políticas educativas globales de naturaleza nacional se incorporan a los mandatos locales $\mathrm{y}$, al mismo tiempo, a partir de entonces, se constituyeron en políticas locales y se desarrollaron con todos los aparatos del Estado, como desarrollador, ejecutor de políticas educativas. Medio, involucrado con dinámicas locales, políticas y sociales que abarcan la realidad educativa. De esta manera, se establece la conexión sobre el sentido de clase asumido por el estado capitalista en la evolución política nacional, en el cual la forma conservadora de desarrollo de la economía desde la colonización incorpora a la burocracia gubernamental los estados de clase propios del período colonizador y, del sentido patrimonial oligárquico de desarrollo en la república, este significado fisiológico está presente en la forma de organización y gestión de los recursos públicos disponibles en la modernidad burguesa brasileña.

Palabras clave: Políticas educativas; Escuela secundaria; Estado de Pará.

\section{Introdução}

Esse artigo se debruça em uma interpretação da política educacional do Ensino Médio desenvolvido pelo Estado Paraense. Busca compreender como as políticas educacionais globais de cunho nacional, se incorporam às injunções locais e, ao mesmo tempo, como a partir de então, elas se constituíram em políticas locais e desenvolvidas com todo aparato do Estado, como elaborador, executor das políticas do Ensino Médio, envolvido com as dinâmicas, políticas e sociais locais que abrangem a realidade educacional.

Discutindo o caráter racional do papel do Estado, onde para além de seu aspecto de elaborador ele sofre anuências das injunções locais, isto é, como próprio executor também econômico da política educacional. Nele a influência partidária, o usufruto dos recursos e o peso dos agentes sociais envolvidos, que determinou suas ações políticas. Isso trouxe consequências essenciais para o desenvolvimento educacional não só nas escolhas dos gestores como nas descentralizações e organização do sistema, sendo determinante inclusive nos destinos curriculares e nas alocações de pessoal e da própria ação escolar. 
Além disso, discutimos a partir dos resultados da pesquisa com gestores educacionais, como a ação do estado estabelece a execução da política, principalmente na legislação e na execução de programas que visem dar corpo às políticas voltadas ao Ensino Médio. Em essência questiona-se qual o sentido teórico-prático do desenvolvimento da política educacional estabelecida pelo Estado Paraense voltado ao Ensino Médio.

\section{Aspectos metodológicos}

O pressuposto básico que se apresenta como eixo norteador da pesquisa desenvolvida, é a compreensão de que a educação se constrói como uma prática social histórica e portanto, é inerente à forma como o ser humano edifica sua sobrevivência e a concepção de mundo no qual está inserido, ou seja, o mundo social e a própria materialidade histórica desse fenômeno dinâmico que é a cotidianidade humana e suas transformações.

No cenário educacional, portanto, é o homem concreto, situado historicamente e em constante relação com seus pares e o seu ambiente de convivência que irá definir os rumos a serem traçados pelas políticas públicas educacionais desenvolvidas pelo Estado e seu reflexo nas ações no espaço dos sistemas, nas escolas e na formação das práticas educacionais.

Nessa perspectiva, a referência metodológica da pesquisa não se constitui apenas como uma questão de métodos e instrumentos de coleta de dados, mas possui um caráter mais amplo, que se estabelece como o eixo estruturante da investigação. Como afirma Menga Ludke (1986) a pesquisa qualitativa, possui sua relevância, à medida que permite ao pesquisador ficar frente ao objeto dentro de uma determinada realidade. E ainda, permite coletar e analisar dados, conceituar e classificar as categorias e critérios que serão analisados de forma flexível, visto que os referenciais e as interpretações teóricas devem ocorrer concomitantes e permanentemente com a perspectiva de ampliar o olhar de quem estuda.

É possível codificar e decodificar pontos importantes em relação ao tema da pesquisa por meio de uma pesquisa qualitativa. Ainda segundo Bogdan e Biklen (2005) a pesquisa qualitativa estabelece o comprometimento do pesquisador com sua realidade e, ao mesmo tempo, abre espaço para superação positivista, com diálogo permanente entre o sujeito que pesquisa e o sujeito que é pesquisado, numa interação contínua. Nessa concepção os autores expressam:

Os investigadores qualitativos frequentam os locais de estudo porque se preocupam com o contexto. Entendem que as ações podem ser melhor compreendidas quando são observadas 
no seu ambiente habitual de ocorrência. Os locais têm de ser entendidos no contexto da história das instituições a que pertencem. Quando os dados em causas são produzidos por sujeitos, como registros oficiais, os investigadores querem saber como e em que circunstâncias é que eles foram elaborados. Quais as circunstâncias históricas e movimentos de que fazem parte? Para o investigador qualitativo divorciar o ato, a palavra ou o gesto do seu contexto é perder de vista o significado (BOGDAN; BIKLEN, 2005, p. 48).

Estes autores consideram que na pesquisa qualitativa a "fonte direta de dados é o ambiente natural e o investigador atua como instrumento principal" (p. 47). Nesse sentido, o pesquisador, deve estar inserido no lócus da pesquisa por um período que possibilite conhecer e registrar, através de várias técnicas, as peculiaridades do objeto em estudo.

Também refletem que nessa abordagem o "interesse da investigação é muito mais no processo do que propriamente no produto" (p. 49), ou seja, está caracterizada pelo caminho de compreensão dos processos, isto é, do cotidiano e das tramas que envolvem os sujeitos da pesquisa. Portanto, em suas perspectivas a pesquisa se efetiva no firme objetivo de captar as representações, os significados, as vivências, enfim, as subjetividades dos sujeitos.

Pela própria característica da pesquisa e o fundamento teórico que a norteia, centrado em uma concepção histórico dialética, a dimensão explicativa, também é considerada como aspecto essencial da apreensão dos dados, pois a mesma busca o aprofundamento da realidade através da explicação dos porquês e ainda a interpretação efetiva das ocorrências dos fatos.

Tal é o caminho que a pesquisa qualitativa favorece que é análise, na qual se busca não apenas a aparência imediata do fenômeno pesquisado, mas a concretude de sua essência. Isto nos leva a procura de suas causas e o contexto sócio-político que está inserido. Ainda na linguagem de Triviños (1987, p. 129):

A investigação histórico-estrutural, porém, aprecia o desenvolvimento do fenômeno não só em sua visão atual que marca apenas o início da análise, como também penetra em sua estrutura íntima, latente, inclusive não viável ou observável a simples observação ou reflexão, para descobrir suas relações e avançar no conhecimento de seus aspectos evolutivos, tratando de identificar as forças decisivas responsáveis por seu desenrolar característico.

Portanto, mediante a natureza do meu objeto de estudo, a pesquisa qualitativa através de suas técnicas e instrumentos de coleta de dados abre caminho para o entendimento da influência dos saberes e experiências dos sujeitos envolvidos no sistema de gestão do Ensino Médio, bem como, do papel que exercem as políticas educacionais desenvolvidas pelo Estado Paraenses. 
Assim, o artigo apresenta mais especificamente o contexto sociopolítico que fundamentam os planos das orientações das políticas educacionais voltadas para o Ensino Médio, que influenciam peremptoriamente no olhar dos gestores da política; tomaremos também, como universo de pesquisa as leis, os decretos os discursos oficiais, para compreendermos as dinâmicas políticas e ideológicas das ações desenvolvidas pelo governo.

Além disso, no desenvolvimento da pesquisa trabalhamos com dados secundários e primários, neste sentido, o levantamento bibliográfico e documental teve como objetivo garantir a construção do arcabouço teórico que dá suporte à pesquisa. Trata-se de uma atitude que permeia todos os momentos do estudo, conquanto que tais investigações se configuraram como um processo contínuo. Empreendimento da pesquisa documental e bibliográfica foi centrada mais especificamente nas discussões acerca da temática pesquisada: contexto sociopolítico e educacional, tanto em nível nacional e local.

A pesquisa teve como foco levantamento de informações acerca dos planos e projetos governamentais para a educação, projetos de lei, resoluções e outros documentos oficiais que ajudaram na compreensão do objeto investigado.

De outro lado, os dados primários, centrados na coleta dos dados, colhidos de acordo com a dinâmica da própria condução da pesquisa. Destacam-se aqui os instrumentos mais recorrentes na tradição de pesquisa no campo educacional, tais como: entrevistas semiestruturadas e observação participante, feitas como os gestores responsáveis da política educacional voltada ao Ensino Médio no Estado do Pará no período estudado.

Dados quanti-qualitativos levantados, buscando-se empreender uma investigação voltada tanto à descrição e a explicação da realidade tal como se apresenta quanto ao desvelamento dos determinantes não explícitos, mas marcantes na definição das políticas educacionais do Ensino Médio estabelecidas no cenário pesquisado.

\section{Contexto das Políticas Públicas Educacionais na Amazônia Paraense}

Na Amazônia Paraense, a maneira como o Estado tem procedido na execução da política e o modo como têm chegado às pessoas que moram nas cidades, bairros, famílias e/ou convivem nas escolas, acabam por estabelecer o sentido que as mesmas assumem nesse universo estudado. Nas últimas décadas o Ensino Médio tem situado como nível de Ensino que mais tem chamado atenção, influenciado principalmente, por ser um período que se define como tempo de juventude. O que tem levado tanto em âmbito internacional entre os organismos multilaterais, 
como na ordem interna do País, este ser tomado como referência nos discursos oficiais sobre o investimento na Educação Básica.

Segundo Krawczyk, o Brasil trouxe para sí a responsabilidade pelo processo de universalização e obrigatoriedade com gratuidade da educação básica, porém com grandes desafios de uma realidade educacional que exige uma ação enérgica capaz de fazer frente a uma profunda dívida social marcada por segregação escolar e desigualdades de oportunidades. Exigências que se manifestam tanto de ordem interna impulsionada pela demanda cada vez crescente da juventude, como pela pressão de caráter internacional. Porém com grandes provocações que tem trazidos percalços efetivos com consequências de diversas ordens inclusive de caráter sistêmico e pedagógico. Em sua linguagem,

Iniciou-se um conjunto de políticas nacionais e estaduais que procuram o aumento da matrícula, permanência e êxitos dos estudantes, afetando as relações de poder na organização e gestão do sistema educacional e no trabalho pedagógico nas escolas. Afetam também as trajetórias escolares dos estudantes e as condições de trabalho docente e o comportamento das famílias. (KRAWZYK, 2014, p. 14).

No entanto, mesmo com expansão do Ensino Fundamental e o crescimento do Ensino Médio, os índices educacionais demonstram que ainda não se foi capaz de superar a desigualdade educacional elevada entre as regiões e segmentos populacionais, urbanos e rurais, étnicos e de gênero. A precarização do ensino, em especial do Médio ainda é um elemento da realidade. A distorção série-idade, condições físicas e materiais frágeis, falta de políticas que garantam a permanência com sucesso, são elementos que evidenciam tal precarização.

Definido, como último nível da Educação Básica, de acordo com a Lei de Diretrizes e Bases da Educação Nacional (LDBEN) - Lei n 9.394/1996 -, os dados são alarmantes, em que pese à prerrogativa legal da progressiva extensão da oferta desse nível de ensino: mais de 50\% dos jovens de 15 a 17 anos não estão matriculados no Ensino Médio, milhões de jovens com mais de 18 anos e adultos não concluíram esse nível, configurando um déficit educacional e uma dívida do poder público com a sociedade.

Nessas perspectivas o Estado contemporâneo se identifica pelas relações que se coloca, seja pelo caráter liberal econômico que responde ao sentido do mercado e do capital, como também pelo seu significado racional burocrático organizador que funda a definição do político e do controle da legislação e da execução de suas políticas. Bem como do conflito e identidade de classe, no qual pela demanda que assume das pressões da sociedade civil, tende a caminhar 
na contradição de respostas ao mercado e ao capital, às exigências interpostas pelos diversos segmentos da sociedade.

Portanto, para o que nos propomos estudar estes elementos teóricos preliminarmente dão o entendimento dos aspectos que envolvem a dinâmica dos conceitos de Estado e Política Educacional na Amazônia Paraense, pois, diferentemente das análises que incorporam esses conceitos como análise sistêmica global, busca-se neste momento compreendê-los a partir das esferas singulares ou locais como acima descrevemos. Tais elementos favorecem a compreensão das injunções dos espaços que definem a realidade dos fenômenos das políticas em educação voltadas para o Ensino Médio, e das características das arenas que são construídas no processo de participação política: seja nos aspectos partidários como na construção da cidadania efetiva.

Essa compreensão do Estado como elaborador, organizador e executor da política educacional se propaga na própria concepção dos indivíduos que compõem o universo da pesquisa seja de professores, coordenadores e gestores do sistema. Em suas falas o Estado a partir de contexto outros que se decidem pelas exigências econômicas, políticas e sociais, organiza e estrutura a legislação e o sentido da política: "quando a gente fala dessas políticas públicas a gente observa que o Estado busca universalizar as políticas em nível de Ensino Médio sem corresponder à realidade local” (PROFESSORA C).

Essas falas reforçam o entendimento do caráter elaborador e executor que assume o papel do Estado na execução das políticas educacionais. Compondo um universo cuja elaboração nem sempre coloca em pauta as dinâmicas locais, mas respondem principalmente a ditames mais de ordem globais definidos seja pela resolução econômica organizadas dos organismos multilaterais como pelos princípios que se fundam pelo Estado nacional. Porém quando se estuda a formatação das políticas educacionais desenvolvidas pelo Estado Paraense algumas características essenciais precisam ser levadas em contexto. Primeiro que esse tempo que se destina para análise responde efetivamente em âmbito tanto nacional como local a priori duas formas de gestão que se intercalam e marcam os sentidos das políticas educacionais voltadas ao Ensino Médio. Mesmo que em essência não se constituam tão divergentes, trazem elementos novos no âmbito da legislação e da execução da política educacional.

Segundo, que no âmbito da organização e da gestão administrativa local, para além da elaboração da legislação, o cotidiano burocrático e a forma como a política educacional se efetiva, ela é resultado de pressões que se situam no sistema, seja de cunho político partidário, bem como das exigências expressas nas reivindicações dos diversos setores sociais e/ou das concepções ideológicas que fundam a dimensão administrativa dos gestores. 
Nesse sentido, quando retorno ao primeiro aspecto, que é sobre as influências do contexto do Estado Nacional e da efetivação das políticas educacionais na realidade paraense compreendo a partir do sentido que Lima (2001) interpreta a dinâmica da organização e gestão do sistema educacional. Sua análise adota a ideia da escola como organização sistêmica que embora se constitua em uma unidade singular suas relações estão definidas a partir de uma visão de meso abordagem sistêmica, onde mesmo que em sua identidade ela possua aspectos próprios de sua atividade cotidiana, encontra-se em volta de elementos organizativos burocráticos, mediadores que recebem sentido, a partir da constituição política administrativa de seus órgãos e do processo normativo inscrito em sua forma de legislação exposta na concepção de ação do Estado.

Em sua interpretação o tipo de abordagem sociológica da organização escolar como unidade social não pode prescindir do entendimento de fatores sejam eles de caráter macros, bem como, do sentido micro dos elementos que intermediam as relações que dão definição a ação no universo escolar. Assim compreende o autor:

Sem ignorar tais elementos, que de fato não pode dispensar ou desprezar, a mesoabordagem da escola parece constituir uma forma de integração de objetos de estudo macroestruturais (o Estado, os sistemas políticos econômicos, a macro organização do sistema escolar, etc.) e de objetos de estudo de tipo microestrutural (a sala de aula, os grupos/subgrupos de formação, os atores e as suas práticas em contextos específicos de ação. (LIMA, 2001, p. 07).

Isto significa que em seu entendimento entre o papel do Estado e os indivíduos envolvidos, entre o sistema educativo e o universo escolar, verifica-se ações e contextos organizacionais concretos que efetivamente se interagem com os diversos elementos, “[...] podendo assim ser distinguidos deles em termos de análise. Deste modo, passa a desenvolverse à organização-escola não apenas centralidade em termos de estudo mas de seu caráter complexo, a heterogeneidade e diversidade [...]" (LIMA, 2001, p. 08), que concretamente a envolve na sua atividade formativa.

Com esse entendimento, de que para além da dinâmica presente no universo da escola é necessário a compreensão de como os elementos da política educacional do Ensino médio nos seus princípios e diretrizes se incorporam ao contexto político econômico do Estado Paraense. Este caminho de caráter mais abrangente que intencionamos interpretar através do contexto inscrito em documentos, projetos e legislações continua sendo fundamentado pelo que o autor chama de plano das orientações para a ação organizacional, no qual está sempre presente e consubstanciado na face oficial do sistema, sempre existente em estatutos, normas e legislações 
etc. E que se constituem em sua linguagem no quadro erigido e fixado através de objetivos oficiais conferindo significado normativo a ação do Estado. Assim ele afirma, "Em termos de procura de racionalidade, estamos perante o modelo-racional legal, isto é, um modelo que toma por referência a racionalidade (a priori) do sistema do ponto de vista da sua administração centralizada" (LIMA, 2001, p. 51). E complementa: "as regras formais obrigam a um desempenho em conformidade, tendo como bases predominantes de legitimação a normatividade, o cumprimento da lei e dos regulamentos, passíveis de controle e de fiscalizações" (LIMA, 2001, p. 51).

Cabe, contudo acrescentar que em seu modelo de análise do sistema escolar, em que define pelo modelo da anarquia organizada, esse aspecto mais abrangente não significa instrumento de verdades absolutas, mas contêm em sua essência, elementos que dão sentido de existência e permanência que legitimam a própria ação do Estado ou do sistema organizacional com sua face burocrática, mas que se interligam e são mediados por diversos setores que podem estabelecer outro significado a esse aparato político, racional e administrativo-legal.

É a partir dessa reflexão que compreendo que o entendimento desse período que serve de pano de fundo para o estudo das políticas educacionais na Amazônia Paraense, deve balizarse nos processos de mudanças que estruturam em um contexto que descrevemos na segunda parte desse trabalho e que possuem reflexos efetivos tanto no contexto político-social como no desenvolvimento das políticas educacionais do Ensino Médio. Encontram-se circunscritas no debate nacional descrito como neoliberal, isto é, de reestruturação do papel do Estado e de uma profunda reforma fiscal. Estabelecidos nos marcos das políticas econômicas e sociais do Governo Fernando Henrique Cardoso.

O que cabe acrescentar na reflexão é que embora esse período estudado não seja o da temporalidade definida na pesquisa, sua compreensão torna-se essencial, pois em última instância o sentido das políticas educacionais instituídas no Plano de Desenvolvimento do Ensino Médio pelo Governo anterior continuará presente na execução dos anos seguintes a que nós propomos estudar. Haverá modificações nas ações políticas do Estado Paraense, mas sua execução pelos percalços administrativos e de gestão tornar-se-ão mais intencionalidades do que uma efetiva implementação.

Quando se vai à temporalidade da pesquisa - a partir de 2007 - a expressão da fala da Gestora do Sistema III, nos demonstra o significado dos anos seguintes de gestão: Nós tivemos um movimento, eu percebo uma vontade, nós tivemos um exercício a nível até acadêmico, de discussão, de formação e até de produção de material, de documentos. Mas isso não se implementou em 
política pública que mudasse, de forma consistente, de forma afirmativa essa dinâmica do Ensino Médio. (GESTORA DO SISTEMA III).

A sua voz desvela o sentido político educacional do momento, um período rico de debate, mas com pouca efetivação na praxidade do universo da escola. Um tempo profícuo de elaboração propositiva de diretrizes e questionamento sobre o Ensino Médio. Isto se completa com a fala do Gestor do Sistema II: "Eu avalio muito positivo esse momento, foi muito rico para mim particularmente, a gente aprendeu muito, cresceu muito, mas, infelizmente, as coisas não têm continuidade".

Essas ponderações nos direcionam a compreensão do ambiente socioeconômico e político que envolve as mudanças que dão suporte às políticas de desenvolvimento do Estado e da educação a partir de 2007. A ordem em essência não diferenciaria. A pauta também era definida pela agenda mais global posta pelo Governo Federal.

Justifica-se por constituir-se de reformas do Estado Nacional que irão refletir peremptoriamente na educação; tanto em âmbito global, como em âmbito local, gestões pressupostamente diferentes no desenvolver do papel do Estado e na definição dos princípios norteadores da educação que em tese determinariam objetivamente o papel do Ensino Médio no Brasil e na Amazônia Paraense.

Destarte, seria o contexto mais global definido pelas ações do Governo Lula que daria o norte do desenvolvimento das políticas mais amplas de governo voltadas as questões socioeconômicas e da educação na Amazônia paraense no período no qual nos propomos estudar. Presumidamente a referência seria de um tempo de mudanças ou reestruturação da agenda política social do governo local, definido de uma maior ação do Estado Paraense nas políticas redistributivas e de maior participação política dos setores sociais na gestão do Estado. Este enfoque se encontra presente na Mensagem do Governo do Estado a Assembleia Legislativa em janeiro de 2007 em seu preâmbulo o approach central são as ações política e econômica apontadas pelo Governo do Presidente Lula como espelho fundante as ações a ser assumida pelo governo local, na sua mensagem a Governadora Ana Júlia faz a seguinte menção: A nossa vitória foi ainda maior, porque sou companheira de luta e de projetos do Presidente Luís Inácio Lula da Silva. É confortante dizer que podemos contar com o Presidente da República. Além do que sabemos que seu primeiro mandato teve êxito porque conseguiu realizar uma justa distribuição de renda, consorciada com a estabilidade nunca vista antes neste País. Ou seja, dois elementos que garantiram o crescimento sustentável com inclusão social e diminuição das desigualdades sociais (PARÁ, 2007, p. 07). 
E acrescentaria que com esse vínculo efetivo à forma de gestão do Governo Federal em vigência, seria possível constituir uma nova agenda que fosse capaz de transformar a face do Estado Paraense criando oportunidades que possibilita que homens e mulheres fossem transformadas “(...) em verdadeiras cidadãs e cidadãos, capazes de alimentar, estudar, trabalhar e exercer plenamente seus direitos, no seio de um Estado integrado ao ente federativo de forma autônoma e cooperativa" (PARÁ, 2007, p. 07). Ao mesmo tempo que reforça essa mentalidade quanto reflete a necessidade de política de ajuste e responsabilidade social acompanhando o que se estabelece em nível nacional, quando afirma: "Nosso governo combinou a Responsabilidade fiscal com a responsabilidade Social como símbolo das mudanças no estilo de governar" (PARÁ, 2007, p. 25).

Esse discurso integra a gestão local ao modelo nacional vigente estruturado em uma política que na dimensão de Tarso Genro seria um novo Estado democrático cuja sua base se pautava na integração na economia de diversos setores nunca contemplados, ou seja, de "demanda de bens básicos para integrar socialmente a população pobre ou em via de empobrecimento" (GENRO, 2000, p. 68) e acrescenta, um choque de economia que envolva uma ampla base social capaz de resistir às oposições geradas no próprio sistema.

Porém, esse entendimento não é de consenso entre os autores que analisam esse momento político social do Estado Brasileiro, para autores como Francisco de Oliveira (2010) essa fase de gestão nacional significava a continuidade das políticas neoliberais centradas principalmente na manutenção do ajuste fiscal e da reforma da previdência ajustado com políticas compensatórias para as populações menos favorecidas.

Por outro lado, autores como Pochman (2010) que instruiu seu entendimento no caminho das contradições de um governo presumidamente de esquerda, mas com um programa de reformas, aponta para superação das políticas econômicas neoliberais e na entrada de uma nova fase que se define por um neodesenvolvimentismo. Pois para ele, o governo Lula caracteriza pela manutenção da estrutura econômica, porém com a retomada dos investimentos pautados em uma agenda de inclusão e crescimento econômico. Centrado principalmente em programas sociais que vão além de políticas compensatórias, como o Bolsa Família, garantia do poder de compras dos salários e inclusão de setores amplos da base popular integrada ao mercado interno produtivo, como construção civil e bens de serviços. Combinado, além disso, com programas formação e qualificação profissional.

Portanto, é a esta última concepção que no âmbito do discurso oficial do Governo do Estado do Pará entra a linguagem de superação de uma gestão centralizada voltada aos ditames 
do mercado. O caminho então a ser trilhado, buscaria partir de uma dinâmica de planejamento, que incorporaria processos de gestão democrática e de participação da população na definição das demandas a serem assumidas pelo Governo nos dois biênios de sua administração.

Esse ponto de vista encontrar-se-á nas definições das políticas públicas e nas ações colocadas no PPA de 2008 a 2011 deliberadas como prioridades a serem assumidas. Essas ações e metas foram compostas nas atividades desenvolvidas pelo Planejamento Territorial ParticipativoPTP, que buscava a partir de assembleias envolvendo os diversos setores sociais e as diferentes regiões do Estado pensadas como território, definir demandas e prioridades nas políticas sociais a serem expandidas pelo Estado Paraense. Assim, então se compunha o plano no preâmbulo norteador das estratégias de ação:

Neste contexto, o Plano Plurianual 2008-2011 foi fundamentado em um modelo inovador de planejamento e gestão, inaugurando uma nova fase no planejamento governamental com a construção e a gestão do Plano a partir de um amplo debate, buscando a implantação de um novo padrão de relação entre Estado e sociedade, marcada pela transparência, solidariedade e corresponsabilidade, consubstanciada no controle social. A sociedade passa, então, a ser o agente de mudança para o desenvolvimento, com uma visão territorial / local de suas demandas sociais, garantido seu espaço neste novo Governo (PPA, 2008, p. 02).

Este aspecto torna-se ainda contundente quando estabelece as ações na criação e desenvolvimento do Planejamento Territorial Participativo como instrumento de referência desse caráter democrático da gestão, buscando, portanto, as diversas dinâmicas e demandas provenientes da real necessidade das populações envolvidas,

O PPA 2008- 2011 "Construindo o Pará de Todas e Todos", traz, como elemento inovador, a incorporação das 12 regiões no processo de elaboração e execução das políticas públicas de longo prazo e, consequentemente, para a construção dos Programas de Governo representando a identidade local. Em corolário, essa visão territorial foi construída a partir da participação popular, por meio das plenárias regionais realizadas nas 12 Regiões de Integração do Estado, espaços em que todo e qualquer cidadão teve voz e voto nas decisões macro a serem implementadas neste Governo (PPA, 2008, p. 03). E acrescentaria:

O modelo de participação foi construído com base na concepção de gestão democrática e radicalmente participativa que norteia o Planejamento Territorial e Participativo (PTP) que tem como premissa a gestão transparente, em suas ações, e democrática, em seus mecanismos de diálogo com a sociedade. Por isso, este modelo impõe uma nova cultura de gestão do Estado com controle social e concretizada na integração territorial do Pará, em torno 
da democratização do debate acerca de um novo modelo de desenvolvimento que respeita a diversidade socioambiental dos macros e microrregiões nas quais suas populações exerçam sua cidadania de forma livre e democrática, empoderando - se socialmente como atores que se realizam na arena pública da participação popular (PPA, 2008, p. 04).

E mais adiante, o documento completa:

O PTP, portanto, objetivou consolidar um estado tonificado na democracia, na participação popular, na gestão descentralizada, no empoderamento dos sujeitos e na preocupação com o desenvolvimento socioeconômico e cultural, visando a utilização dos recursos públicos em favor da inclusão social. Assim, o PTP se constitui enquanto um conjunto de atos realizados coletivamente para programa ações do governo, oportunizando a descentralização da gestão pública e integrando os atores sociais nas decisões governamentais. É construído nos territórios, nas 12 regiões de integração regional concebidas com um campo de forças, uma teia ou rede de relações sociais que se organizam em determinados espaços com objetivos diversos (PPA, 2008, p. 05).

Quando se retorna aos aspectos educacionais, o sentido do discurso está novamente inserido as políticas nacionais e a necessidade de superação dos gargalos deixados pela gestão anterior no Estado. A opção pelo desenvolvimento do processo de municipalização do Ensino Fundamental desencadeado no Governo Jatene fora tida como equívoco, pois os dados que a Governadora apresentava na mensagem à Assembleia Legislativa trazia como fundamento o decréscimo do número de vagas no sistema estadual de educação. Na sua linguagem, o Estado Paraense havia extinguido mais de 100.000 vagas na educação e os municípios haviam absorvido apenas 60 mil vagas, o que exigia uma nova ação do Estado no que se refere a esse nível de ensino. E reafirmava essa realidade apresentando os seguintes dados:

As políticas educacionais não tiveram como consequência o aumento da escolaridade no Estado. Se considerarmos o percentual de pessoas alfabetizadas com 15 anos e mais de idade, no que se refere aos anos de estudo, 41,04\% tinham mais de oito anos de estudos em 2001, e esse mesmo indicador caiu para 37,62\% em 2004 (PARÁ, 2007, p. 31).

No entanto, mesmo com todo esse aspecto de criticidade apontado pela nova gestão governamental do Estado Paraense, não vão ter grandes mudanças na execução das políticas educacionais. Embora a construção teórica esteja fundada nos parâmetros apontados pela gestão democrática, isto não significa dizer que, objetivamente, se logrou progressos significativos na incorporação das demandas sociais locais. Poderíamos até afirmar que na concepção de dar novos instrumentos institucionais de direitos e conquistas observaram-se avanços importantes, contudo sem um reflexo direto no sistema e no universo da escola. 
Os dados da pesquisa revelam tal realidade, principalmente na escuta dos gestores do sistema desse período, há o reconhecimento de um tempo de reflexão e elaboração de diretrizes para um perfil de uma nova gestão com outros parâmetros de legislação e sentido de reorganização do sistema, no entanto com muitos percalços administrativos. A começar pelo ambiente institucional da Secretaria de Educação e pela forma de condução da gestão governamental que durante os quatro anos de Governo foram modificados na educação o Secretário Executivo em cinco vezes, o que, simbolizava a quebra no processo de continuidade das ações desenvolvida por cada um deles na política educacional.

$\mathrm{Na}$ interpretação da Gestora do Sistema I, o fato acima descrito se constituía um dos efeitos mais negativos na execução da política à descontinuidade na gestão, a troca em sequência de secretários inviabilizou uma ação efetiva na educação do Estado. Pois mesmos que viessem do mesmo alinhamento político seus modos de ver e pensar a educação acabam sendo diferentes, o que traz consequência efetiva no planejamento e organização da política educacional. Assim, a mesma completa:

Acho que em qualquer troca de gestor, ela prejudica porque quebra uma rotina de trabalho na Secretaria, nas escolas. Nem sempre tem continuidade das políticas que já estavam em andamento, mesmo sendo de mesmo partido. Cada gestor entende que tem que colocar de sua maneira, do seu modo. Então isso prejudica a população, prejudicam os alunos, os professores. Então, a meu ver, isto criou uma instabilidade geral (GESTORA DO SISTEMA I)

Com esse mesmo sentido comunicava o Gestor do Sistema II, a falta de continuidade implicava até no desempenho do funcionamento institucional, em sua expressão: "Professor, dizia o funcionário, "depois que o senhor sair, daqui a pouco o senhor sai e vem outro." Então, porque que eu levava a verdade? Cada um chega, chega como dono da verdade. Olha, no governo Ana Júlia foram cinco secretários de educação, cinco equipes diferentes, o que implicava indiretamente em novos olhares para a política educacional" (Gestor do Sistema II).

O que se fortalece também na fala da Gestora do Sistema III:

Você sabe que nós tivemos uma rotatividade muito grande, cinco secretários em quatro anos. Então nós não conseguimos viver a continuidade de uma ideia. Nós começamos com o primeiro Secretário, nós tivemos um ano, a segunda Secretária, ela veio e ficou mais ou menos, um ano e meio, aí nós tivemos a terceira Secretária que ficou menos de um ano, quarto, e quinta Secretária; a quinta secretária assumiu por dois meses, aí, pense! Por mais que nós tivéssemos vontade, infelizmente, mudava os secretários, mudava as equipes (Gestora do Sistema III). 
Apesar dessas constatações de fragilidade na administração do sistema educacional a mentalidade era de um caminho cuja referência passaria pela gestão democrática, princípio já exposto na concepção de governo, já demonstrada em nível dos discursos propositivos que seriam transformados em leis. Ainda na mensagem da Governadora a superação do quadro educacional que herdara, emanaria efetivamente pela necessidade de construção de uma nova educação a ser pensada principalmente pela elaboração do Plano Estadual de Educação, em sua fala,

Fica a lição da necessidade de uma construção coletiva do Plano Estadual de Educação que possa estabelecer uma opção ética por um ideal de educação no Estado. E pode nascer de um esforço colaborativo da sociedade paraense e que obedeça aos princípios da gestão democrática" (PARÁ, 2007, p. 31).

Ações buscaram efetivamente dar outra dinâmica ao processo educacional, que se relacionava com a mentalidade descrita nas atividades de planejamento e gestão do governo. Teve início um conjunto de seminários, fori, reuniões, com o intuito de reformular a legislação de ensino; diversas publicações foram encaminhadas às escolas organismos e representações da sociedade civil com a intenção de redefinir uma nova política voltada para a educação básica. Seguindo essa orientação construiu as Conferências de Educação, tanto municipais, regionais e a estadual para elaboração do Plano Estadual de Educação, o que no final do governo fora aprovado sob a Lei $\mathrm{n}^{\circ} 7.441$, de julho de 2010.

Essa expectativa colhida nos documentos e nas atividades propostas é reforçada também na escuta dos sujeitos da pesquisa durante esse período. Na expressão da Gestora do Sistema III, a ideia era de que na gestão do Estado, o mandato se constituiria de pelo menos oito anos para que as formulações e as experimentações fossem universalizadas no sistema e vivenciadas nas escolas. No entanto, o tempo de gestão do Governo foi rápido não conseguindo trazer mudança na praxicidade do universo escolar, pois teria sido abortada pelo pouco tempo de permanência no poder. Em sua fala,

Eu não posso negar que nós tivemos assim, momentos riquíssimos, não só da CONAI, como da parte de formação, fomos chamados em encontros muito ricos; tivemos encontros, deslocamentos de grupos ligados a Universidade Federal, a UEPA e até oportunidades de ouvir outros estudiosos, de São Paulo, de outras universidades, mas infelizmente, eu diria assim, na prática, a vivência dessa transformação ela foi sacrificada pelo pouco tempo de mandato (GESTORA DO SISTEMA III).

Essa reflexão é também confirmada na fala dos demais gestores do sistema entrevistados, em especial da Gestora do Sistema I que fora ouvida, nas suas ações foi colocada 
como prioridade a elaboração de política permanente com a efetivação de além do Plano Estadual de Educação, o Plano de cargos e salário, bem como, para dentro do Plano Estadual a gestão democrática com a provação de eleição direta para diretor:

Eu deixei três medidas: o PARFOR, Plano de Cargos e Salário e o Plano Estadual de Educação. O PARFOR eu instalei um Fórum, presidi, selecionei a $1^{\text {a }}$ turma, está aí já com os alunos todos em sala. O Plano de Cargos e Salário nós tivemos que travar um embate interno no governo. Convencer de que o Plano de Cargos e Salário tinha que acontecer. Além da Eleições diretas para diretor incluídas no Plano Estadual de Educação (GESTORA DO SISTEMA I).

Este intento em nível geral voltado a reformulação da Educação Básica a Secretaria de Educação do Estado editou no ano de 2008 os caderno de reflexão cujo título versava sobre: “A Educação Básica no Pará: elementos para uma política educacional democrática e de qualidade Pará Todos”, o intento era estabelecer a reforma do ensino do Estado, buscando princípios que se coadunasse com a Gestão Democrática, do qual definia cinco elementos essenciais para transformação educação: função social da escola pública, gestão democrática da educação, política curricular e organização didática da educação básica, inclusão e diversidade, formação de professores e valorização dos profissionais de educação (SEDUC, 2008). Não se constituía em uma elaboração definitiva transformada em legislação, mas um conjunto de reflexão que tinha como intencionalidade buscar elementos para estruturação de diretrizes a partir do ambiente escolar.

Este fato se afirmou nas letras do Plano Estadual de Educação quando reforça a ideia de construção de novos parâmetros para educação do Estado Paraense, reconhecendo a Conferência Estadual como o elemento fundante para as modificações a serem implementadas pelas políticas educacionais do Estado. Nas letras do Plano Estadual se ratifica o que havia sido proposto pelos cadernos de reflexão,

A Conferência Estadual de Educação se constitui na mais importante instância, em nível estadual, para a definição de propostas de ações prioritárias para a educação no Pará. É um momento decisivo no qual serão concebidas e projetadas diretrizes de descentralização políticoadministrativa e de garantia da participação popular, ratificando a proposta de uma educação como direito universal básico e bem social público, condição de emancipação e cidadão como sujeito de direitos e compromisso social, por meio de uma gestão cooperativa entre as diferentes esferas de poder e a participação social como construção coletiva, tendo em vista o desenvolvimento sustentável e o respeito às diversidades étnico-raciais, de gênero, de 
orientação sexual e religiosas, na perspectiva da construção de um sistema único de educação (PEE / PARÁ, 2010, p. 09).

Nesse sentido ratifica a compreensão exposta por Lima (2001) de que entre as proposições de caráter do plano das orientações para a ação organizacional e sua efetivação, há elementos mediadores que dão a acepção do que está sendo proposto, mesmo que no plano das efetivações dessas orientações não signifique que se reproduzem da mesma forma como foram elaboradas.

Essa dimensão teórica irá se confirmar no contexto de interpretação das políticas educacionais do Estado Paraense voltadas ao Ensino Médio. Três sentidos se revelam no ambiente estudado circunspecto pela pesquisa. O primeiro na criticidade do olhar dos informantes sobre as políticas desenvolvidas pelo governo anterior, apresentado no sentido da ressignificação da política e na precariedade da organização do sistema a esse nível de ensino; segundo na ideia da reestruturação e superação da política anterior circunscrevendo como um momento de elaboração e, por último a não execução da política pelos percalços administrativos encontrados no período do mandato o que levou a continuidade da dualidade sistêmica presente na continuidade das concepções do PEM anterior no universo da escola.

Segundo Documento Base do Ensino Médio Integrado da SEDUC (2008, p. 08) sobre a qualidade do Ensino Médio no Estado Pará os índices são críticos, a taxa de aprovação é de $67 \%$, a de reprovação é de $13 \%$, a evasão escolar com um índice de $25 \%$. O Índice de Desenvolvimento da Educação Básica (IDEB) é de 2,6. Além disso, o número de professores também é indesejável são 11.348 docentes para 337.995 alunos, numa média de um docente para cada 29,8 discentes. No sistema Modular de Ensino (SOME) vigente em 345 localidades, com um quantitativo de 827 professores distribuídos em 88 municípios, em que a relação professor por aluno é em média de 28,5. Fato que nos leva ir à busca de compreender como a política e seus resultados se incorporam e refletem nas injunções da realidade local.

Os dados e a expressão da fala do Gestor do Sistema II traduzem esse primeiro olhar da precarização sobre o desenvolvimento da política do governo anterior direcionado ao Ensino Médio, ele é contundente em afirmar que não havia uma política definida do Estado e/ou da Secretaria de Educação voltada para o Ensino Médio: "Bom, primeiro, eu não recebi nada dos meus gestores anteriores, eles não tinham nenhum relatório, nenhum projeto" (GESTOR DO SISTEMA II).

O que aparecia segundo ele, era uma definição dos anos 80 do século passado, elaborado pela antiga política desenvolvida pelo Governo Gueiros, em sua fala: "O último projeto educacional do estado do Pará, antes de eu ter entrado, foi ainda do período Gueiros" (GESTOR DO SISTEMA II). 
A partir de então, não teria mais nenhum documento norteador da política educacional destinada ao Ensino Médio. Assim ele completava,

Depois do Gueiros teve anos de Jader e Carlos Santos, oito anos de Almir, quatro anos de governos de Jatene. Não sei se teve algum PMDB pelo meio, mas não teve nenhum projeto educacional, uma política, um documento que orientasse os gestores e professores das escolas como proceder, nenhum (GESTOR DO SISTEMA II).

O caminho trilhado era a expansão definida pelas políticas gerais do Governo Federal dos anos 1990 refletida no plano de metas estabelecido no projeto Alvorada que apontava diretrizes gerais de expansão e universalização do Ensino Médio,

Cheguei e perguntei para os técnicos: "vem cá, e quem é que orienta vocês, aí eles dizem: "o Alvorada". Alvorada foi um programa do Governo Federal, na época do governo Fernando Henrique, que era um programa de redimensionamento das escolas, que não era um projeto pedagógico, tinha ali algumas diretrizes, algumas orientações, mas era um único documento, digamos assim, orientador das práticas educacionais no Estado do Pará (GESTOR DO SISTEMA II).

$\mathrm{Na}$ verdade, era o que anteriormente refletimos sobre o Governo precedente a 2007 sobre o Programa de Expansão do Ensino Médio (PEM) organizado desde os anos de administração do Governador Almir Gabriel e continuado pelo seu sucessor. O que definia e/ou ainda responde a política do Ensino Médio são os princípios da proposta curricular das diretrizes de 2000 e do perfil da LDBN organizadas nos Parâmetros Curriculares Nacionais - PCNs, na concepção de uma formação cuja ênfase encontra-se no sentido das habilidades e competências, porém, muito mais situado na perspectiva de expansão tendo como fundamento uma formação voltada para a continuidade dos estudos reproduzindo a histórica dicotomia entre a formação e a necessidade do mundo do trabalho.

O que responde ao que Dagmar Zibas aprofunda sobre as reformas que estava no início do século, reforçado pelas transformações econômicas que exigiam outros parâmetros formativos para juventude que adentrava o Ensino Médio. Para ela, desde o final dos anos 90, havia uma discussão eloquente na sociedade mundial e nacional que defendia "(...) a necessidade de formação dos jovens com base em novos conhecimentos e competências, de modo que possam interagir com as profundas mudanças socioeconômicas, tecnológicas e culturais da contemporaneidade” (ZIBAS, 2005, p. 02). Mas se que deliberaram em uma visão vinculada as dinâmicas propostas pelo mercado desconhecendo as próprias necessidades nacionais e, porque não dizer as dinâmicas regionais do Estado Paraense. Essa perspectiva 
ressoa na fala dos Gestores do Sistema quanto nas dos Gestores de Escolas e Professores: a ausência de uma política construída para o Ensino Médio no Estado do Pará.

Essa constatação nos leva ao segundo sentido que aparece na pesquisa: da interpretação sobre a perspectiva do Governo do Estado a partir de 2007, ou seja, de sua ação voltada ao Ensino Médio, que se compreende na ideia da reestruturação e superação da política anterior, circunscrevendo como um momento de discussão e elaboração de parâmetros diferentes para a política no Estado Paraense. Marcaria o caminho que se aproximaria das propostas nacionais que buscavam superar os ditames da reforma anterior a 2003. A ênfase seria de superar a dualidade sistêmica traduzida nos governos anteriores.

Através da Secretaria de Estado de Educação - SEDUC - o Estado reincorporou as escolas de Trabalho e Produção ao sistema formal de ensino, da mesma forma que buscou através de diversas publicações estabelecer novos marcos ao Ensino Médio, tendo como influência os parâmetros definidos pelo governo Federal tanto nas balizas do Decreto $\mathrm{n}^{\circ}$ 5.154/2004, quanto da Resolução $n^{\circ}$ 04/2010 que reformula as diretrizes curriculares da educação básica, tendo em vista redefinir o caráter identitário do Ensino Médio, resgatado no conceito da integração, formação geral e mundo do trabalho.

Essa perspectiva do contexto governamental encontra ressonância nos dados levantados na pesquisa, segundo o Gestor do Sistema II. Em essência o Estado Paraense, em particular na sua gestão, definiu diretrizes amplas centrado na integração, buscando dar um norte nas diversas experiências e execução do Ensino Médio no Estado. No qual a primeira ação estabelecida foi fazer uma reestruturação do Ensino Médio no seio da Gestão na própria Secretaria de Educação, segundo ele, quando assumiu a administração estabeleceu um novo modelo, primeiro: “(...) foi acabar com as duas redes, trazendo para a Secretaria a gestão das escolas de trabalho e produção, eu não poderia trabalhar com aquele esquema que eu não concordava, não tinha como fazer a gestão, porque eu ficaria com a responsabilidade do ensino médio e técnico”.

Além disso, sendo o Ensino Médio etapa final da educação básica teria como fundamento precípuo o significado de desenvolver o processo de autonomia do cidadão respeitando as diversas dimensões da vida. Assim completa o documento:

Desde o ano de 2007 a Secretaria de Estado de Educação deu encaminhamento ao processo de construção da política de educação básica, com base nas deliberações da Conferência que aprovou as diretrizes, metas e objetivos para elaboração do Plano Estadual de Educação. Em relação ao Ensino Médio, as deliberações indicaram que o projeto do ensino médio integrado fosse assumido como política pública no Estado do Pará, visando tornar as 
escolas públicas de Ensino Médio mais atrativas aos jovens adultos e a assegurar espaços e formas de aprendizagens diversificados (SEDUC, 2008, p. 11).

Entretanto, muitas dificuldades de implementação se destacam nas falas dos gestores do sistema entrevistado, na voz do Gestor do Sistema II, além do pouco tempo de gestão no governo as pressões internas exercidas traziam percalços efetivos à consecução da ação planejada, em que a influência negativa da burocracia e da política nem sempre correspondem às necessidades e realidades educacionais, assim ele expressava: "Como diz Paulo Freire, os interesses envolvidos são muito grande e, uma burocracia também muito grande também. A SEDUC foi feita para não funcionar, o dia que funcionar, muita gente vai perder dinheiro e vai perder poder". E acrescenta,

Quando a Secretária assumiu a Secretaria de Educação tinham 12 mil processos, 12 mil, 13 mil, 14 mil processos parados de pagamento, mas era processo de diária de professor, uma ajuda de custo de algum, uma diferença do salário do porteiro, um professor que foi dar uma palestra, uma empresa que construiu um muro, então, coisa de 500 reais, 2000 reais, 5000 reais. Doze... eu não me lembro se era 12 ou se era 14 mil processos parados que não foram pagos (GESTOR DO SISTEMA II).

O que na sua fala esses percalços administrativos traziam consequências efetivas nas realizações da Secretaria de Educação influenciando negativamente na execução das ações, em que construções de escolas deveriam ser concretizadas ou mesmo reformadas, mas que pelas dificuldades apresentadas isso não acontecia.

Além dessa dificuldade premente na execução da gestão, o tempo financeiro é outro percalço administrativo forte e que leva a favorecimentos. A necessidade urgente dos gastos a serem executados no período limite, mas execuções de ações desnecessárias pela necessidade do gasto, principalmente, em de evitar perda de recursos, assim ele reafirma,

No final das contas, quando chega a setembro, aí começa a correria, não gastou o dinheiro! Faz um grande evento, reúne 2000 professores. Num evento você gasta sete milhões de reais! Você, diz que teve formação, porque reuniu um contingente de pessoas: você paga diária, paga transporte, paga alimentação, paga aquela parafernália em um evento que não tem efetividade e, favorece interesses de setores que não são da educação. Por isso que eu digo, o dia que a burocracia funcionar, isso não iria acontecer (GESTOR DO SISTEMA II).

Mas se isso se dá no âmbito da burocracia, se reforça na influência partidária e de interesses empresariais nos gastos dos recursos educacionais, o que nos leva ao caráter fisiológico estabelecido na estrutura do Estado. Os interesses interpostos nas falas dos sujeitos entrevistados demonstram o caráter da pressão exercida por aspectos outros, que não é o 
desenvolvimento da política educacional voltada ao Ensino Médio. Mas, há sim, o sentido negativo da influência partidária determinado tanto pelos desvios a outros fins, como de elementos de fora da estrutura do sistema educacional como de políticos e de ações necessárias e imediatas do governo. Assim continua na fala do Gestores do Sistema, contundente na voz seguinte,

Também uma coisa muito ruim é a interferência política, então tem político que pensa que é dono de escola, ele vai indicar o diretor porque ele quer; eu sou parlamentar daquela área, eu que indico o diretor daquela escola. Então, tem muita cobrança, mas não é cobrança no bom sentido, uma interferência mesmo da política, mas é da política partidária, dos interesses partidários, às vezes, dos interesses mais mesquinhos que interferem na vida da Secretaria de Educação (GESTOR DO SISTEMA II).

Esse mesmo sentido surge na dinâmica dos interesses partidários e particulares do orçamento financeiro anual da educação no Estado Paraense. Segundo as vozes dos mesmos sujeitos ouvidos o orçamento da Secretaria Estadual de educação é um dos maiores do Estado suplantando de diversos municípios o que leva no âmbito da gestão a permanente pressão de setores tanto de ordem mais global, bem como, na da dinâmica estabelecida da relação do setor público com a os interesses da iniciativa privada.

\section{Considerações Finais}

O mesmo sentido tem ressonância na fala da Gestora do Sistema I ouvida, os recursos conseguidos tornaram-se elementos de disputas internas dificultando então uma ação planejada das ações de sua gestão voltadas ao desenvolvimento do Ensino Médio. Em sua fala, durante sua gestão em seu orçamento foi acrescido verbas destinadas ao Ensino Médio, porém esse montante quando transformada em elementos financeiros o grande problema encontrava-se de que a gestão do recurso se dá a partir do Tesouro Estadual, determinado, portanto, pelo peso da burocracia estatal.

Assim o que se pode concluir, que durante esse período estudado, as ações buscaram efetivamente dar outra dinâmica ao processo educacional, que se relacionava com a mentalidade descrita nas atividades de planejamento e gestão do governo. Teve início um conjunto de seminários, fori, reuniões, com o intuito de reformular a legislação de ensino; diversas publicações foram encaminhadas às escolas organismos e representações da sociedade civil com a intenção de redefinir uma nova política voltada para a educação básica. Nesse sentido, houve as Conferências de Educação, tanto municipais, regionais e a estadual para 
elaboração do Plano Estadual de Educação, o que no final do governo fora aprovado sob a Lei $\mathrm{n}^{\mathrm{o}} 7.441$, de julho de 2010 .

Durante esse período o Estado Paraense procurou no âmbito do sistema elaborar diretrizes cujo princípio seria a integração, com a proposição da separação da formação profissional desvinculada do sistema, trazendo para a Secretaria de Educação as escolas de trabalho e produção e transformando-as em escola tecnológicas. Buscando, portanto, dar a política educacional voltada ao Ensino Médio outra dimensão que corresponderia adequar aos ditames nacionais que estruturam novos parâmetros para a política nacional desse nível de Ensino.

O que se pode afirmar é que para além da elaboração da legislação, o dia-a-dia burocrático e a maneira como a política educacional acontece, ela é consequência das contradições que se situam no sistema, tanto de caráter político partidário, bem como, das exigências expressas nos setores privados, além, das reivindicações e necessidades das esferas sociais e/ou das concepções ideológicas e/ou políticas que se instituiu na dimensão administrativa dos gestores.

\section{REFERÊNCIAS}

BOGDAN, Robert \& BIKLEN, Sari. Investigação Qualitativa em Educação: uma introdução à teoria e aos métodos. Porto - Portugal: Porto Editora, 1994. BRASIL -2005.

\section{BRASIL - Lei de Diretrizes e Bases da Educação Nacional. Lei no . 9.394, de 20 de Dezembro de 1996. Brasília, 2007.}

COUTINHO, Cláudio N. A Hegemonia da Pequena Política. In: OLIVEIRA, Francisco de \& BRAGA, Ruy \& RIZEK, Cibele(orgs). Hegemonia às Avessas: economia, política e cultura na era da servidão financeira. São Paulo: Boitempo. 2010.

FERNANDES, Florestan. Mudanças Sociais no Brasil: $4^{\mathrm{a}}$ ed - Editora Expressão Popular: São Paulo, 2008.

GENRO, Tarso. Estado, mercado e democracia no "olho" da crise. In: RATTNER, Henrique (organizador). Brasil no limiar do século XXI: alternativas para a construção de uma sociedade sustentável. São Paulo: Edusp, 2000.

LÜDKE, Menga \& ANDRÉ, Marli E. D. A. Pesquisa em educação: abordagens qualitativas. São Paulo: EPU, 1986.

LIMA, Licínio C. A Escola como Organização Educativa: uma abordagem sociológica. São Paulo: Cortez, 2001. 
KRAWCZYK, Nora Rut. Conhecimento Crítico e Política Educacional: um diálogo difícil, mas necessário. In: KRAWCZYK, Nora (Org). Sociologia do Ensino Médio: crítica ao economicismo na política educacional. São Paulo: Cortez, 2014.

OLIVEIRA, Francisco de. Hegemonia às Avessas. In: OLIVEIRA, Francisco de \& BRAGA, Ruy \& RIZEK, Cibele(orgs). Hegemonia às Avessas: economia, política e cultura na era da servidão financeira. São Paulo: Boitempo. 2010.

POCHMANN, Marcio. Desenvolvimento e Perspectivas Novas para o Brasil. São Paulo: Cortez, 2010.

PARA, Governo do. Plano Plurianual - 2008-2011. Belém, 2008 .

PARÁ, Mensagem do Governador à Assembleia Legislativa - 2007. Belém, 2007

PARÁ, Secretaria Executiva de Educação. Plano Estadual de Educação - 2010.

PARÁ, Secretaria Executiva de Educação. Plano de Expansão e Melhoria do Ensino Médio - PEM - 1999. Belém, 1999.

PARA, Secretaria de Estado de Educação. O Ensino Médio Integrado no Pará como

Política Pública. Organização textual por Adriana Maria de Nazaré de Sousa Porto, Ronaldo Marcos de Lima Araújo, Elinilze Guedes Teodoro. - Belém: SEDUC, 2008.

TRIVIÑOS, Augusto N. S. Introdução à Pesquisa em Ciências Sociais: A Pesquisa Qualitativa em Educação. São Paulo: Atlas, 1987. 282.

ZIBAS, Dagmar M. L. Refundar o ensino médio? Alguns antecedentes e atuais desdobramentos das políticas dos anos de 1990. Educ. Soc. [online]. 2005.

\section{SOBRE OS AUTORES:}

\section{Afonso Welliton de Sousa Nascimento}

Doutor em Educação pela Universidade Federal do Ceará (UFC). Professor da Universidade Federal do Pará (UFPA), Brasil. Atua no Programa de Pós-Graduação em Cidades, Territórios e Identidades - PPGCITI/UFPA. Líder do Grupo de Estudos e Pesquisa em Sociedade, Estado e Educação. E-mail: afonsosn@ufpa.br

(iD) http://orcid.org/0000-0002-2351-4683 


\section{Yvens Ely Martins Cordeiro}

Doutor em Ciências Agrárias pela Universidade Federal Rural da Amazônia (UFRA). Professor da Universidade Federal do Pará (UFPA), Brasil. Atua no Programa de Pós-Graduação em Cidades, Territórios e Identidades - PPGCITI/UFPA. É pesquisador do Grupo de Estudos Diversidade Socioagroambiental na Amazônia (GEDAF) e líder dlo do grupo de pesquisa Estudos da Biodiversidade e Sustentabilidade na Amazônia Tocantina (GEBIOS). E-mail: yemcordeiro@ufpa.br

(iD http://orcid.org/0000-0003-0596-002X

\section{Francinei Bentes Tavares}

Doutor em Sociologia pela Universidade Federal do Rio Grande do Sul (UFRGS). Professor da Universidade Federal do Pará (UFPA), Brasil. Atua no Programa de Pós-Graduação em Cidades, Territórios e Identidades - PPGCITI/UFPA. É pesquisador do Grupo de Estudos Diversidade Socioagroambiental na Amazônia (GEDAF) e do grupo de pesquisa Desenvolvimento Rural e Inovação Sociotécnica (DRIS). E-mail: francinei@ufpa.br

(iD http://orcid.org/0000-0003-1170-6538

\section{José Ribamar Furtado de Souza}

Doutor em Sociologia do Desenvolvimento e Ciências Políticas pela London School Of Economics And Political Science Universidade de Londres, UL, Grã-Bretanha. Professor da Universidade Federal do Pará (UFPA), Brasil. Atua no Programa de Pós-Graduação em Cidades, Territórios e Identidades - PPGCITI/UFPA. É pesquisador dos grupos de pesquisa do CNPq: Movimentos Sociais, Educação Popular e Escola; Desenho e Análise de Sistemas Agrícola e Tecnologias Sustentáveis e Etnodesenvolvimento. E-mail: furtado.riba@gmail.com (iD http://orcid.org/0000-0002-5487-6310 